\title{
Effect of Temperature on Corrosion and Cathodic Protection of X65 Pipeline Steel in 3.5\% NaCl Solution
}

\author{
Yingjie Liu, Zhiming Gao*, Xibo Lu, Liqin Wang \\ School of Material Science and Technology, Tianjin University, Tianjin, 30072, China \\ "E-mail: gaozhiming@tju.edu.cn
}

doi: $10.20964 / 2019.01 .54$

Received: 11 September 2018 / Accepted: 8 November 2018 / Published: 30 November 2018

\begin{abstract}
In this investigation, polarization curve, electrochemical impedance spectroscopy and hydrogen permeation measurements were used to observe the corrosion behavior and cathodic protection of X65 under the influence of temperature. The results show that, with an increase in temperature, $\mathrm{I}_{\text {corr }}$ increased. $\mathrm{E}_{\text {corr }}$ decreased and electrochemical impedance decreased, which indicates that corrosion resistance of X65 steel was weakened. As the temperature was increased, $\mathrm{D}_{\mathrm{e}}$ deceased and $\mathrm{c}_{0}$ increased. The defects in X65 steel can block the hydrogen diffusion, but the hydrogen concentration in the specimen increased, which increased the risk of hydrogen embrittlement of X65 steel. As the hydrogen charge potential was shifted negatively, the current density first decreased and then increased, which indicated that the influence of hydrogen air masses in X65 is limited.
\end{abstract}

Keywords: temperature; X65 pipeline steel; polarization; hydrogen permeation

\section{FULL TEXT}

(C) 2019 The Authors. Published by ESG (www.electrochemsci.org). This article is an open access article distributed under the terms and conditions of the Creative Commons Attribution license (http://creativecommons.org/licenses/by/4.0/). 